\title{
The Impact of Risk Factors Reduction Scenarios on Hospital Admissions, Disability-Adjusted Life Years and the Hospitalisation Cost of Cardiovascular Disease in Thailand
}

\author{
Rungkarn Inthavong1, Khaled Khatab ${ }^{2,3 *}$, Malcolm Whitfield2', Karen Collins' ${ }^{2}$, Mubarak Ismail2, \\ Maruf Raheem ${ }^{4}$
}

${ }^{1}$ Department of Public Health, Loei Rajabhat University, Loei, Thailand

${ }^{2}$ Faculty of Health and Wellbeing, Sheffield Hallam University, Sheffield, UK

${ }^{3}$ Department of Arts and Sciences, Ohio University, Elson Hall, Zanesville, OH, USA

${ }^{4}$ Departments of Engineering and Mathematics, Sheffield Hallam University, Sheffield, UK

Email: ^k.khatab@shu.ac.uk

How to cite this paper: Inthavong, R., Khatab, K., Whitfield, M., Collins, K., Ismail, M. and Raheem, M. (2020) The Impact of Risk Factors Reduction Scenarios on Hospital Admissions, Disability-Adjusted Life Years and the Hospitalisation Cost of Cardiovascular Disease in Thailand. Open Access Library Journal, 7: e6160.

https://doi.org/10.4236/oalib.1106160

Received: February 12, 2020

Accepted: March 17, 2020

Published: March 20, 2020

Copyright (๑) 2020 by author(s) and Open Access Library Inc.

This work is licensed under the Creative Commons Attribution International License (CC BY 4.0).

http://creativecommons.org/licenses/by/4.0/

\section{(c) (i) Open Access}

\begin{abstract}
Cardiovascular disease (CVD) is considered to be one of the leading health issues in Thailand. CVD not only contributes to an increase in the number of hospital admissions year by year but also impacts on the rising health care expenditure for the treatment and long-term care of CVD patients. Therefore, this study is aimed at examining the impacts of risk reduction strategies on the number of CVD hospital admissions, Disability-Adjusted Life Years (DALYs) and the costs of hospitalisation. To estimate such impacts a CVD cost-offset model was applied using a Microsoft Excel spreadsheet. The number of the mid-year population was classified by age, gender and the CVD risk factor profiles from the recent Thai National Health Examination Survey (NHES) IV. This survey was chosen as the baseline population. The CVD risk factor profiles included age, gender, systolic blood pressure, total cholesterol, and smoking status. The Asia-Pacific Collaborative Cohort Study (APCCS) equation was applied to predict the probability of developing CVD over the next eight-year period. Estimates on the following were obtained from the model: 1) the CVD events both fatal and non-fatal; 2) the difference between the projected number of deaths and the actual number of deaths in that population; 3) the number of patients who are expected to live with CVD; 4) the DALYs from the estimated number of fatal and non-fatal events; 5) the cost of hospital admissions. Four CVD risk strategy scenarios were investigated as follows: 1) the do-nothing scenario; 2) the optimistic scenario; 3) achieve the UN millennium development goal; and 4) the worst-case sce-
\end{abstract}


nario. The findings showed that over the next eight years, there are likely to be 3,297,428 recorded cases of CVD; 5,870,049 cases of DALYs; and, approximately $B 57,000$ million, ( $\$ 1.9$ billion), is projected as the total cost of hospital admissions. However, if the current health policy can reduce the levels of risk factors as defined in the optimistic scenario or such policy meets the specifications of the UN millennium development goal, there would be a significant reduction in the number of hospital admissions. These are estimated to be a reduction of 522,179 male and 515,416 female cases. With these results, it is expected that health care costs would save approximately $B 9000$ million, (\$298.3 million), for CVD and 900,000 million DALYs over the next eight years. However, if there is an upward trend in the risk factors as predicted in the worst-case scenario, then there will be an increase of 428,220 CVD cases; consequently, DALYs cases may rise by 766,029 while the hospitalisation costs may increase by approximately $B 7000$ million, ( $\$ 232.1$ million). Based on our findings, reducing the levels of CVD risk factors in the population will drastically reduce: 1 ) the number of CVD cases; 2) DALYs cases; and 3) health care costs. Therefore it is recommended that the health policy should enhance the primary prevention programs which would be targeted at reducing the CVD risk factors in the population.

\section{Subject Areas}

Cardiology, Public Health

\section{Keywords}

Cardiovascular Disease (CVD), Disability-Adjusted Life Years (DALYs), Cost of Admission, Risk Factors

\section{Introduction}

CVD is considered one of the main potential health care problems in Thailand. The burden of the disease and related injuries from a study in Thailand estimated that 1,146,064 DALYs were lost from CVD, which includes both ischemic heart diseases (IHD) and stroke [1]. The DALYs lost from stroke was ranked as the third-highest in men and the second highest in women, whereas, IHD was rated as the sixth and fourth highest cause of death and disability in men and women, respectively. Although the overall mortality rate in Thailand has reduced over the past decade due to improvements in the health care services, the prevalence of CVD, however, continues to rise [2]; this has led to an increasing need for medical and long term care for CVD patients. Consequently, CVD has become a burden for both patients and the health service providers in terms of health care expenditure.

The increase in the prevalence of CVD is related to socio-economic and lifestyle changes in the population in Thailand which have increased the risk of CVD [3] [4]. It has been proved that classical CVD risk factors such as high 
blood pressure, high total cholesterol and cigarette smoking are related to the incidence of CVD [5] [6] [7] [8]. The Ministry of Public Health, Thailand has encouraged the reduction of these modifiable risk factors at the population level. Many public health interventions have been implemented, such as health education, advocating physical activity, promoting healthy diets and changing the smoking regulations [9]. However, this raises the following questions: will the investment in public health programs reduce the further demand for health care in the population; and, if so, how much benefit will be gained from reducing the risk factors at the population level?

In terms of CVD modelling, several studies have projected the number of future CVD events and health care expenditure for the country, based on the current information of the risk factors levels in the population [10] [11] [12]. Some studies have found that reducing the level of risk factors in the population will subsequently reduce the number of deaths and disability from CVD, and at the same time help to save on the costs of hospital admissions [13] [14] [15]. Many studies in the health economics field have investigated the cost-effectiveness of secondary prevention programs and treatment strategies, such as comparing the multidrug regimen for prevention of CVD [16]-[20], coronary artery revascularization procedures [21], and the treatment of high blood pressure [22].

This study; however, focuses on the primary prevention strategies that should be implemented within the general population, to prevent them from being admitted into the hospital due to CVD. The study aims to estimate the impact of public health risk reduction strategies on the potential benefits of this investment. The mathematical model conducted assessed the modified risk equation from the Asia Pacific Cohort [2] study collaboration. The eight-year probability of CVD events has been calculated based on the most recent population-level risk factors information. The model estimates the number of patients living with CVD conditions, such as IHD and stroke; and those with the burden of the DALYs diseases that are likely to be admitted into the hospital. The outcomes of interest in this study are the impacts in terms of the number of CVD hospital admissions avoided, the DALYs saving and the health care financial savings.

\section{Materials and Methods}

\subsection{The CVD Cost-Offset Model}

A CVD cost-offset model [16] has been applied to: 1) Estimate the number of CVD hospital admissions during the next eight-year period; 2) Predict the burden of disease in terms of DALYs; and 3) Estimate the cost of hospital admissions due to CVD conditions. The CVD cost-offset model was used to assess the impact of risk reduction strategies on the number of hospital admissions, DALYs and direct health care costs. The effects of changing the risk factors at the population level have been investigated through four different scenarios. The analysis process is described below.

The CVD cost-offset model was computed using a Microsoft Excel spread- 
sheet. The baseline population size was defined by the most recent relevant data available which included gender and age group information. The CVD risk factors such as age, systolic blood pressure, total cholesterol, and regular smoking obtained from the Thai 4th National Health Examination Survey (NHES) IV [2] [23], were used as the input parameters to represent the mean level of risk factors within the Thai population and identified by age group and gender. Table 1 shows the input data of the cost-offset model based on the number of the mid-year population and the risk factor profiles.

The probability of experiencing CVD events within an eight-year period was obtained using the Asia-Pacific Cohort Study (APCS) equations [4]. Age, systolic blood pressure, total cholesterol and smoking were included as risk factors in the equation. From the model, the probability of CVD events within an eight-year period was estimated by age group and gender. Then, the eight-year probability of CVD events was multiplied by the number of the mid-year population to get the estimated number of CVD events over the next eight years. However, the APCS equation calculated the probability of all CVD events, which included both fatal and non-fatal CVD events.

Table 1. The number of the mid-year population and the mean level of risk factors by age group and gender in 2009. Thai 4th national health examination survey.

\begin{tabular}{|c|c|c|c|c|c|}
\hline \multirow{2}{*}{ Men } & \multirow{2}{*}{$\begin{array}{l}\text { Mid-year } \\
\text { population } \\
2009\end{array}$} & \multicolumn{4}{|c|}{ The mean level of risk factors } \\
\hline & & $\begin{array}{c}\text { Age } \\
\text { (years) }\end{array}$ & $\begin{array}{c}\text { SBP } \\
(\mathrm{mmHg})\end{array}$ & $\begin{array}{c}\mathrm{TC} \\
(\mathrm{mmol})\end{array}$ & $\begin{array}{c}\text { Smoking } \\
\text { prevalence (\%) }\end{array}$ \\
\hline $15-24$ & $4,683,981$ & 18.76 & 117.24 & 4.60 & $28.5 \%$ \\
\hline $25-34$ & $5,149,508$ & 29.92 & 120.80 & 5.27 & $42.3 \%$ \\
\hline $35-44$ & $5,154,963$ & 39.75 & 122.56 & 5.43 & $39.9 \%$ \\
\hline $45-54$ & $4,058,120$ & 49.33 & 126.44 & 5.46 & $42.6 \%$ \\
\hline $55-64$ & $2,399,309$ & 60.11 & 131.44 & 5.40 & $34.4 \%$ \\
\hline $65-74$ & $1,362,752$ & 69.17 & 134.60 & 5.31 & $30.5 \%$ \\
\hline$\geq 75$ & 749,125 & 79.22 & 137.22 & 5.20 & $23.5 \%$ \\
\hline Total & $23,557,758$ & 52.80 & 128.39 & 5.28 & $34.0 \%$ \\
\hline \multirow[b]{2}{*}{ Women } & Mid-year & \multicolumn{4}{|c|}{ The mean level of risk factors } \\
\hline & $\begin{array}{l}\text { population } \\
2009\end{array}$ & $\begin{array}{c}\text { Age } \\
\text { (years) }\end{array}$ & $\begin{array}{c}\text { SBP } \\
(\mathrm{mmHg})\end{array}$ & $\begin{array}{c}\text { TC } \\
(\mathrm{mmol})\end{array}$ & $\begin{array}{c}\text { Smoking } \\
\text { prevalence (\%) }\end{array}$ \\
\hline $15-24$ & $4,532,018$ & 18.97 & 106.19 & 4.90 & $0.7 \%$ \\
\hline $25-34$ & $5,130,746$ & 29.87 & 110.19 & 5.21 & $1.4 \%$ \\
\hline $35-44$ & $5,408,488$ & 39.65 & 116.04 & 5.30 & $1.8 \%$ \\
\hline $45-54$ & $4,388,770$ & 49.10 & 123.92 & 5.70 & $2.6 \%$ \\
\hline $55-64$ & $2,694,633$ & 60.02 & 129.45 & 5.92 & $3.0 \%$ \\
\hline $65-74$ & $1,655,159$ & 69.24 & 134.53 & 5.80 & $3.5 \%$ \\
\hline$\geq 75$ & $1,086,374$ & 79.48 & 139.19 & 5.66 & $5.2 \%$ \\
\hline Total & $24,896,188$ & 52.60 & 124.70 & 5.58 & $3.0 \%$ \\
\hline
\end{tabular}


The number of CVD events which caused mortality was estimated using the average 10-year probability of dying from CVD in the general Thai population from 1996 to 2006, classified by age and gender. The likelihood of dying from CVD is shown in (Table A1 \& Table A2). The number of people who are likely to die from CVD was estimated by multiplying the number of estimated CVD events with the probability of dying from CVD. Then, the model deducted the number of people who are likely to die from CVD to obtain the number of people who will be alive with CVD conditions. The outcomes of interest are the number of people with CVD who are alive and the number of deaths from CVD conditions over the eight-year period.

\subsection{Disability Adjusted Life Years (DALYs)}

Once the model had estimated the number of CVD events over an eight-year period, the total DALYs for each age group and gender were calculated as the summation of the years lost due to disability, (YLD), and the years of life lost due to premature death (YLL). Therefore, DALYs will present the burden of CVD which includes both the non-fatal burden and the burden of premature death. The calculation procedure follows the WHO national burden of disease studies [24].

$$
D A L Y=Y L D+Y L L
$$

where: YLD = number of years lost due to disability.

YLL $=$ Number of years of life lost due to premature death.

\subsection{Discounting and Age Weighting}

It is standard practice for a health economic analysis to discount future benefits [25]. This study has applied a $3 \%$ discount rate to years of life lost in the future, to estimate the net present value of years of life lost and for adjusting both future costs and health outcomes as recommended in the Global Burden of Disease study project [26] and the burden of disease study project in Thailand [27]. The assumption of using the age weight was based on the social preference which values a year of life in a younger adult higher than that of a year lived by someone in an elderly age group because the younger adult is considered as being in the labour force which has a more economic productivity value than the elderly age group.

\subsection{Calculating YLL}

YLL represents the number of years of life lost due to premature death which is calculated by multiplying the number of deaths with the standard life expectancies in each age-gender group.

$$
\mathrm{YLL}=N \times L
$$

where: $N=$ number of deaths and $L=$ Standard life expectancy at age of death in years. 
The estimated number of deaths in each age group was entered into the spreadsheet to calculate YLL. The average age at death for each age group was calculated by using the mid-point of age at death in each age interval. Then, the standard life expectancies of these average age at death was calculated by interpolation between the standard life expectancies at the exact ages of death given from the West standard life tables [28] by the single year of age.

With a $3 \%$ discounting and uniform age weights; YLL was computed using the formula:

$$
\mathrm{YLL}=\frac{N}{0.03}\left(1-\mathrm{e}^{-0.03 \mathrm{~L}}\right)
$$

where: $N=$ number of deaths; and $L=$ Standard life expectancy at age of death in years taking into account the $3 \%$ discount rate and age weight.

\subsection{Calculating YLD}

YLD presents the years lost due to disability which is the main component of DALYs. The basic formula of YLD is:

$$
\mathrm{YLD}=I \times D W \times L
$$

where: $I=$ the number of incidence cases in the reference period.

$D W=$ the disability weight.

$L=$ the average duration of disability in years.

In this analysis, the estimated number of people who are alive with CVD conditions by age and gender was entered into the spreadsheet as the number of incidence cases occurring during the eight-year period (I). The disability weight that was used as the average disability weight was from the GBD study undertaken in 2010 and was set at 0.18 for all CVD conditions.

The disability weight by CVD conditions of the GBD study is shown in Table A3. The average age onset of the disability and the duration of disability was calculated by using DISMOD II software [29].

DISMOD II software was developed by Jan J Barendregt, Department of Public Health of Erasmus University, Netherlands [30]. This software developed sophisticated methods to measure the causes and patterns of disease in populations and was used as an analytical tool in the GBD study to check the consistency of various data and for estimating the incidence, prevalence, duration and, fatality events. DISMODII has been commonly used in YLD calculations for estimating the incidence and duration of the disease from information available about a country. An underlying generic disease model concept has been developed in DISMOD software to explore the causal relationships and the disease process as shown in Figure 1.

The number of the mid-year population, the background mortality, the prevalence of CVD and the CVD mortality rate in the Thai population classified by age and gender has been entered as the input information into the DISMOD software. This analysis assumed the remission rate from CVD is equal to zero. 


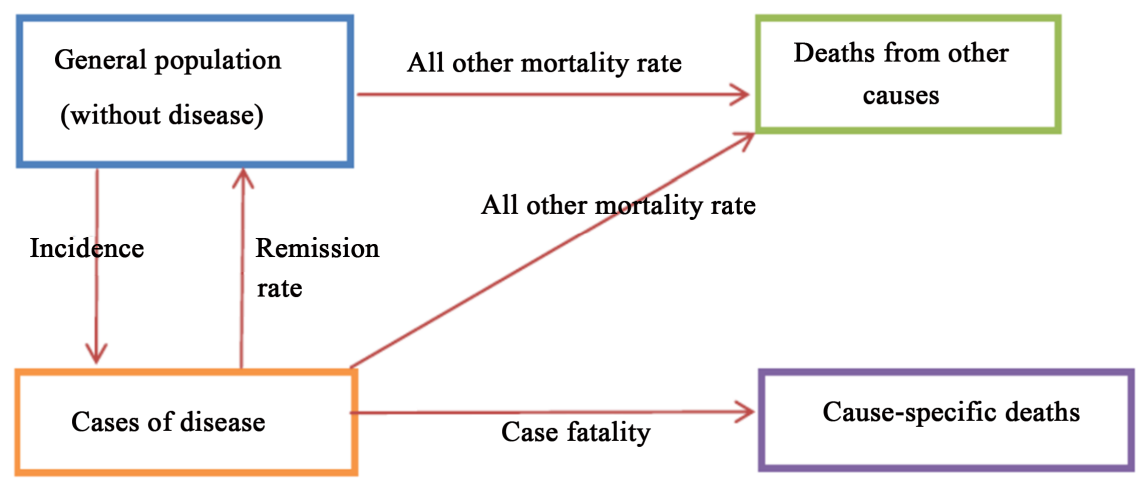

Figure 1. Conceptual generic disease model in DISMOD software (Barendregt et al., 2003).

The study estimated the onset of getting CVD and the duration of the disability from CVD by age and gender.

\subsection{Health Care Cost for CVD Patients}

The average total cost of hospital admissions from CVD was calculated from the inpatient services in Thailand. The costing data obtained from the national health security office includes the universal coverage health care scheme. The results of the health care costs were as reported in [31]. The health care service providers spent $B 32,884$, (\$1090.3), per patient on IHD, $B 25,618$, (\$849.6), per patient on strokes and B21,921, (\$726.9), per patient on all CVD conditions. Because of the limitations of the APCS equation, which estimates the total CVD incidence only, the average cost of all CVD conditions has been used to estimate the total health care costs for the next eight years. The estimated total health care cost was computed by multiplying the average cost per patient with the estimated number of CVD cases. However, this analysis is based on 2009 prices; therefore the discount rate has been applied to these costs to estimate the present value of the health care expenditure.

\subsection{Impact of Changing CVD Risk Factors}

The model was used to consider the CVD risk reduction scenarios which targeted the following three CVD risk factors; systolic blood pressure, total cholesterol, and prevalence of smoking at the population level. Some of the underlying assumptions of the CVD cost offset analysis include: 1) the population structure and the health care system remaining unchanged from those of $2009 ; 2$ ) no change in the population figure, classified by age group and gender over time; and 3) the mean age for the respective age groups remains the same as in the model. From the model, we estimated the impact of changing the risk factors on the number of CVD patients, the number of DALYs, and the cost of hospitalisation in four different scenarios. Table 2 shows a summary of changing the percentages of the risk factors against those scenarios.

The grouping for different scenarios analysed in this study was as follows: 
Table 2. Summary of the risk reduction scenarios for the CVD cost-offset model.

\begin{tabular}{lccc}
\hline & \multicolumn{3}{c}{ \% Change of the risk factors level } \\
\cline { 2 - 4 } & $\begin{array}{c}\text { Systolic blood } \\
\text { pressure }\end{array}$ & $\begin{array}{c}\text { Total } \\
\text { Cholesterol }\end{array}$ & Smoking \\
\hline 1) Do nothing scenario & $0 \%$ & $0 \%$ & $0 \%$ \\
2) The optimistic scenario & $-5 \%$ & $-5 \%$ & $-5 \%$ \\
3) Reach the UN millennium development goal & $-5 \%$ & $0 \%$ & $-30 \%$ \\
4) The worst case scenario & $+3.35 \%$ & $+11.7 \%$ & $-30 \%$ \\
\hline
\end{tabular}

1) Do nothing scenario: this scenario assumes that there is no change in CVD risk factors over time. The level of CVD risk factors remains the same.

2) The optimistic scenario: this scenario assumes that all CVD risk factors have been reduced in the population through public health initiative strategies. The target risk factors have been reduced by $5 \%$.

3) Reach the UN millennium development goal; this scenario estimates what will happen if the risk reduction strategies in Thailand can achieve the UN millennium development goals. The goals' main target is to reduce $25 \%$ of the global premature mortality from non-communicable disease (NCDs) based on the 2010 levels and to achieve it by 2025 [32]; the goal, referred to by some studies as the " $25 \times 25$ " target [33]. The target risk reductions are a reduction of $30 \%$ in the prevalence of tobacco smoking; reducing alcohol consumption by $10 \%$. The reduction of $30 \%$ in the average salt intake of the population, prevents the rising incidence of obesity, reduces $25 \%$ of the prevalence of high blood pressure and stops the rise in the prevalence of diabetes. Based on the available information for the model, this scenario analysis is targeted at reducing $30 \%$ of the smoking rate and assumed that the level of systolic blood pressure stroke is reduced by $5 \%$ to achieve this goal, and the other risk factors remain the same.

4) The worst-case scenario: This scenario assumes that the trend of risk factors in the population will be changed according to the information provided by the WHO global observatory, Thailand's country profile data [34]. The trends of the risk factors of the Thai population who are aged 25 years and, over have been presented in (Tables A4-A6).

From 1980 to 2009 , there was a $+3.35 \%$ increase in the level of systolic blood pressure in the population and $+11.7 \%$ increase in the total cholesterol level. Meanwhile, the population smoking rate reduced by $30 \%$ because of the effectiveness of the smoking regulation policy in Thailand [35].

\section{Results}

\subsection{The Estimated Number of CVD Patients over an 8 Year Period}

Table 3 shows the estimated number of CVD patients over the next eight years by age group, gender and risk reduction scenarios. The model estimates the highest number of patients appear in the "worst-case scenario" which is $3,725,649$ patients and the second-highest figure is in the "do nothing scenario" 
Table 3. Estimated number of CVD patients over an eight-year period at different scenarios.

\begin{tabular}{|c|c|c|c|c|c|c|c|c|c|}
\hline Conditions & Age group & $15-24$ & $25-34$ & $35-44$ & $45-54$ & $55-64$ & $65-74$ & $\geq 75$ & Total \\
\hline \multirow{3}{*}{$\begin{array}{l}\text { Do nothing } \\
\text { scenario }\end{array}$} & Men & 6617 & 16,168 & 4658 & 94,021 & 31,198 & 589,000 & 545,177 & $1,609,550$ \\
\hline & Women & 3662 & 10,240 & 38,912 & 93,534 & 300,332 & 586,461 & 654,736 & $1,687,878$ \\
\hline & Total & 10,279 & 26,409 & 85,491 & 187,555 & 612,320 & $1,175,461$ & $1,199,913$ & $3,297,428$ \\
\hline \multirow{3}{*}{$\begin{array}{l}\text { Optimistic } \\
\text { scenario }\end{array}$} & Men & 5502 & 13,311 & 38,269 & 76,909 & 254,802 & 482,299 & 450,836 & $1,321,927$ \\
\hline & Women & 3220 & 8959 & 33,821 & 80,592 & 257,736 & 503,081 & 565,912 & $1,453,321$ \\
\hline & Total & 8721 & 22,270 & 72,090 & 157,501 & 512,538 & 985,380 & $1,016,749$ & $2,775,249$ \\
\hline \multirow{3}{*}{$\begin{array}{l}\text { Reaching UN } \\
\text { millennium } \\
\text { goal }\end{array}$} & Men & 5492 & 13,181 & 37,999 & 76,213 & 254,127 & 482,308 & 453,004 & $1,322,324$ \\
\hline & Women & 3239 & 9013 & 34,016 & 81,045 & 259,161 & 505,518 & 567,697 & $1,459,688$ \\
\hline & Total & 8732 & 22,193 & 72,016 & 157,258 & 513,287 & 987,826 & $1,020,700$ & $2,782,012$ \\
\hline \multirow{3}{*}{$\begin{array}{c}\text { Worst } \\
\text { case } \\
\text { scenario }\end{array}$} & Men & 7522 & 18,315 & 53,043 & 107,066 & 358,514 & 677,311 & 625,333 & $1,847,104$ \\
\hline & Women & 4033 & 11,316 & 43,173 & 104,367 & 335,897 & 655,003 & 724,758 & $1,878,546$ \\
\hline & Total & 11,555 & 29,630 & 96,215 & 211,433 & 694,411 & $1,332,314$ & $1,350,091$ & $3,725,649$ \\
\hline
\end{tabular}

which is $3,297,428$ patients. However, if public health interventions lead to a reduction in the risk factor levels of CVD, as it is anticipated in the "optimistic scenario", the estimated number of CVD patients will consequently reduce to 2,755,249 patients. Additionally, if the health policies achieve the UN Millennium development goal, the number of total CVD patients will decrease to 2,782,012 patients.

When comparing the estimated number between men and women by age group and the risk reduction scenarios; overall, the model predicts the number of CVD patients would be higher amongst women than men. However, the UN millennium goal scenario estimated the number of male CVD patients to be higher than the figures for women in most age groups except at age 75 years and over. This might be because reducing cigarette smoking by $30 \%$, could have a higher impact on men as they have a higher prevalence of regular smoking than women (Table A2). When comparing the total estimated number of CVD patients by age group and the risk reduction scenarios, the estimated number of CVD patients increases respectively, with the increase in age in both men and women. The worst-case scenario estimated the highest number of CVD patients, followed by the do-nothing scenario. The optimistic scenario and reaching the UN millennium development goal estimated nearly the same reduction in the number of patients (Table A1).

\subsection{The Estimated DALYs over 8 Year Period}

Table 4 shows the estimation of the absolute total DALYs and DALYs lost from CVD per 1000 populations over the next eight years by age group gender and the risk reduction of different scenarios. The highest DALYs overall is in the worst-case scenario, which has a total loss of 6,636,078 DALYs. The second highest is in the do-nothing scenario which has a total loss of 5,870,049 DALYs. 
Table 4. The estimated absolute total DALYs over an eight-year period within the different scenarios.

\begin{tabular}{|c|c|c|c|c|c|c|c|c|c|c|c|c|}
\hline \multirow[t]{2}{*}{ Age } & \multicolumn{3}{|c|}{ Do nothing scenario } & \multicolumn{3}{|c|}{ Optimistic scenario } & \multicolumn{3}{|c|}{$\begin{array}{l}\text { Reaching the } \\
\text { UN millennium goal }\end{array}$} & \multicolumn{3}{|c|}{ Worst case scenario } \\
\hline & Men & Women & Total & Men & Women & Total & Men & Women & Total & Men & Women & Total \\
\hline $15-24$ & 6671 & 262 & 12,932 & 5546 & 5505 & 11,052 & 5537 & 5539 & 11,076 & 7583 & 896 & 14,479 \\
\hline $25-34$ & 24,581 & 24,124 & 48,706 & 20,237 & 21,106 & 41,343 & 20,039 & 21,232 & 41,271 & 27,844 & 26,657 & 54,502 \\
\hline $35-44$ & 95,837 & 104,830 & 200,667 & 78,738 & 91,115 & 169,853 & 78,184 & 91,64 & 169,825 & 109,135 & 116,309 & 225,444 \\
\hline $45-54$ & 224,123 & 244,975 & 469,098 & 183,333 & 211,079 & 394,412 & 181,674 & 212,265 & 393,938 & 255,221 & 273,346 & 528,566 \\
\hline $55-64$ & 720,474 & 698,020 & $1,418,494$ & 588,415 & 599,018 & $1,187,433$ & 586,855 & 602,330 & $1,189,186$ & 827,917 & 780,677 & $1,608,594$ \\
\hline $65-74$ & $1,124,054$ & $1,093,675$ & $2,217,730$ & 920,424 & 938,183 & $1,858,607$ & 920,442 & 942,727 & $1,863,169$ & $1,292,588$ & $1,221,498$ & $2,514,086$ \\
\hline$\geq 75$ & 681,299 & 821,122 & $1,502,421$ & 563,403 & 709,726 & $1,273,129$ & 566,112 & 711,963 & $1,278,075$ & 781,469 & 908,938 & $1,690,407$ \\
\hline Total & $2,877,040$ & $2,993,009$ & $5,870,049$ & $2,360,096$ & $2,575,732$ & $4,935,828$ & $2,358,842$ & $2,587,697$ & $4,946,540$ & $3,301,757$ & $3,334,322$ & $6,636,078$ \\
\hline
\end{tabular}

Further, when the model assumed that the CVD risk factors had been reduced, as in the optimistic scenario, the total DALYs lost will be reduced to $4,935,828$ DALYs. Moreover, if the model assumed that CVD risk factors could be reduced as in the UN millennium goal scenario, the total DALYs lost will be reduced to $4,946,540$. Both the optimistic scenario and the UN millennium goal scenarios estimated the DALYs as nearly the same.

When comparing DALYs across the age groups, it was found that the number of DALYs lost from CVD increases respectively with an increase in the age group. The DALYs figure is higher in older adults, (age 35 years and older) than in younger adults (ages 15 to 34 ). The absolute total DALYs is highest at ages 65 to 74 years across the four scenarios $(1,199,375,1,003,599,1,006,104,1,360,930$, respectively).

Table 5 presents the summary results of the CVD cost-offset model compared against the four scenarios analyses and the impact of changing CVD risk factors, on the number of CVD hospital admissions, total costs of hospitalisation and the DALYs. The do-nothing scenario in the model estimated that over the next eight-year period there will be 3,297,428 CVD patients if the levels of risk factors remain the same. However, if the levels of risk factors are reduced as in the optimistic scenario, (all risk factors reduce by $5 \%$ ), it will reduce the number of CVD hospital admissions by 522,179 people. Additionally, if health interventions can achieve the UN millennium development goal, there will be a reduction in the number of CVD hospital admissions by 515,416 people. Conversely, if the trend of risk factors increases amongst the population as in the worst-case scenario, the number of CVD hospital admissions is estimated to be 3,725,649 representing an increase of 428,220 CVD patients.

In terms of the total cost of hospitalisation, when applying the discount rate of $3 \%$, it is estimated that health service providers would spend B57.1 thousand million, (\$1.9 thousand million), on medical expenditure for CVD patients over the next eight-year period. However, if the health interventions can reduce the 
Table 5. Summary of the CVD cost-offset model showing the four different scenarios.

\begin{tabular}{|c|c|c|c|c|}
\hline \multirow[b]{2}{*}{ Conditions } & \multicolumn{4}{|c|}{ Scenario } \\
\hline & $\begin{array}{l}\text { 1) Do nothing } \\
\text { scenario }\end{array}$ & $\begin{array}{l}\text { 2) Optimistic } \\
\text { scenario }\end{array}$ & $\begin{array}{l}\text { 3) Archive the UN millennium } \\
\text { development goal }\end{array}$ & $\begin{array}{l}\text { 4) Worst case } \\
\text { scenario }\end{array}$ \\
\hline Number of CVD patients & $3,297,428$ & $2,775,249$ & $2,782,012$ & $3,725,649$ \\
\hline $\begin{array}{l}\text { Number of CVD hospital } \\
\text { admission saving, compare to } \\
\text { "Do nothing scenario" }\end{array}$ & - ref & 522,179 (saving) & 515,416 (saving) & 428,220 (increase) \\
\hline Total cost (THB) & $72,282,962,149$ & $60,836,250,852$ & $60,984,521,378$ & $81,669,994,287$ \\
\hline $\begin{array}{c}\text { Total cost (THB) of hospitalization } \\
\text { with } 3 \% \text { Discount rate }\end{array}$ & $57,060,837,804$ & $48,024,698,204$ & $48,141,744,326$ & $64,471,047,657$ \\
\hline Cost of hospitalisation saving (THB) & - ref & $9,036,139,600$ (saving) & $8,919,039,478$ (saving) & $7,410,209,853$ (increase) \\
\hline Total DALYs (years) & $5,870,049$ & $4,935,828$ & $4,946,540$ & $6,636,078$ \\
\hline DALYs saving (years) & - ref & 934,221 (saving) & 923,509 (saving) & 766,029 (increase) \\
\hline
\end{tabular}

levels of risk factors as in the optimistic scenario, there will be a $\$ 9036$ million, (\$299.6 million), saving on the hospitalisation costs. In addition, if the health policy can achieve the UN millennium development goal, it will save $\$ 8919$ million, ( $\$ 295.8$ million), on health care expenditure. Conversely, if the trend of CVD risk factors continually increases as in the worst-case scenario, the health care expenditure will increase by B7410 million, (\$245.7 million), over the next 8 year period.

Furthermore, the cost offset model estimated that 5,870,049 DALYs would be lost due to CVD in Thailand over the next eight years if the levels of risk factors remain the same as in 2009. However, the government would be able to save 934,221 DALYs if all levels of risk factors could be reduced as in the optimistic scenario. Moreover, if the health policy can reach the UN millennium development target, there will be 923,509 DALYs saving in the next eight years. Or, if the trend of CVD risk factors continuously increases as in the worst-case scenario, the total DALYs will increase to 6,636,078 DALYs during the next eight-year period, which would be an increase of 766,029 DALYs overall, in the Thai population.

\section{Discussion}

In 2012 there were 327,435 CVD patient admissions to hospitals with a total health care expenditure of about $\$ 7177$ million, (\$238 million). With regard to the burden of disease (BOD), the estimated total DALYs of IHD and Stroke together were 1,146,064 DALYs in 2012 [9]. If the levels of CVD risk factors remain the same, the number of CVD patients will increase approximately 10 fold and the total DALYs of CVD will increase to 5,870,049 DALYs over the next eight-year period. However, if the trend of risk factors increases as in the worst-case scenario, the number of CVD patients will significantly increase (Table 3 and Table 5). As a consequence, the health care expenditure will also 
increase as well as the DALYs increasing (Table 4 and Table 5).

The CVD cost off-set model has estimated that there are potential benefits of reducing the CVD risk factors at the population level. The optimistic risk reduction scenario and reaching the UN millennium goal scenario are both estimated to have the potential benefit of reducing CVD risk factors on the number of CVD hospitalisations avoided, the total cost of hospital admissions savings and the DALYs saving. Both these scenarios demonstrate similar savings although the UN millennium goal does not take into account the reduction of total cholesterol, there are still high impacts on reducing the level of systolic blood pressure and reducing the prevalence of smoking.

In terms of the DALYs estimation, the DALYs calculation incorporated an age weight which considers the value of the years of life lost at an elderly age to be less than in younger adults. The use of age-weighting is controversial because the societal perspective is concerned about economic productivity, and the value of the years of life are weighted differently among age groups. Nonetheless, from an equality perspective, the values of the years of life are weighted equally for all age groups. However, the applied model in this research is flexible enough to estimate DALYs with or without using age-weighting. When applying age weights in the analysis, it was found that DALYs in the younger age group, (15 - 34) had increased and DALYs in the older age group had decreased.

Additionally, this analysis used the standard life-table, with West Level 26 to calculate the life expectancy in the population. Following the global burden of disease (GBD) and BOD studies, conducted in Thailand, such standard life table was adopted, as against the country's life table, for comparing the results with the other studies. However, the DALYs estimation in this study used the recent Thailand specific life table in 2012 in its' calculations. When applying the country-specific life table to calculate DALYs, it was found that the number of DALYs lost was slightly lower, compared to the standard life table. This is because the standard life table has a higher life expectancy at birth than in the Thailand life table. The life expectancy at birth, according to the standard life table is 80 years in men and 82.5 years in women. While the life expectancy at birth in the Thailand life table in 2012 is 71 years in men and 79 years in women.

\subsection{The Strength of the Study}

This study provides information for the health policy developers to plan and invest in primary prevention programs for chronic diseases such as CVD, rather than waiting until the problems occur. In terms of the implications for policy and practice in Thailand, some primary interventions have already been successfully implemented, such as the smoking regulations which have reduced the prevalence of smoking in the Thai population over the last decade [36]. However, some primary prevention programs such as promoting a healthy diet and undertaking physical activity were not evaluated with respect to their impact on reducing the risk factors of CVD or whether CVD has increased within the population. This is because CVD is caused by a combination of risk factors and it is 
difficult to measure the impact on the health benefits over a short-term period. The CVD cost-offset model can be used as a financial tool in helping to develop the health policy for long-term planning and targeting the investment in primary prevention programs for reducing the instances of CVD. The findings in this study show that there will be significant benefits of reducing the CVD risk factors by reducing the number of hospitalisations, reduction of the burden of disease (DALYs) and savings on the future health care expenditure.

Additionally, the CVD cost-offset model that has been developed in this study used the APCS equation as the risk engine to calculate the probability of instances of CVD events during the eight-year period. The APCS equation is generalisable for applying to other Asian populations because it was derived from the pools of data from cohort studies around Asia. Therefore, this model is able to be replicated and applied to other settings in Asian countries, if the essential information of the population data and the risk factors profiles are available.

\subsection{Limitations of the Study}

There are some limitations to the CVD cost-offset model. The first limitation is that the modelling was conducted under limited conditions with some underlying assumptions. The model is static and compares the estimation at two points of time from 2009 and over the next 8 year period. The model assumed that the number and population structure by age group and gender remains the same, but the reality is that people in the cohort will age. Several studies have suggested that Thailand will become an aging society by 2050 because of the falling fertility rate in the Thai population [36]. It was estimated that in a few decades, Thailand will, for the first time, have a greater population aged 60 years and over than the population aged less than 15 years old [37]. Therefore, the population structure in the future may be different from now because there may be more people in the elderly age groups.

Secondly, CVD risk factors are modifiable. Some risk factors might vary with the age difference and can change over time. Younger adults and older adults experience different levels of risk factors. For example, older adults may experience high blood pressure more than younger adults. Some behavioural risk factors are dynamic which may change anytime based on individual behaviours, such as cigarette smoking. This model was not able to capture any dynamic changing of the CVD risk factors of the individual because the estimation was based on the mean level of risk factors by each age group and gender.

Lastly, the model uses the APCS equation to calculate the eight-year probability of acquiring CVD. This equation has some limitations in terms of the number of independent variables, such as age, gender, systolic blood pressure, total cholesterol level and cigarette smoking status. Some potential risk factors such as diabetic status and BMI level were not included in the equation, which may have the effect of underestimating the risk of CVD in people who have a high BMI or diabetes. Furthermore, although the equation can estimate the overall probabili- 
ty of acquiring CVD, it lacks the capacity to determine the probability of specific CVD conditions, such as stroke and IHD, separately. However, this equation is suitable for use within Asian populations. It has been validated in the performance of the equations within the Thai cohort [4] and also in this study [38]. The model could perform a more precise estimation if the country-specific CVD risk assessment equations were available.

\section{Conclusions}

Findings from this study suggest that reducing any combination of the CVD risk factors can reduce instances of acquiring CVD in a healthy population, as well as savings in the burden of disease in terms of DALYs and savings on health care expenditure.

If the public health initiatives could either attain the UN millennium development goal or a reduction of 5\% in the CVD's risk factors, the health service provider would be able to save approximately $\$ 9000$ million, (\$298.4 million), and about 900,000 DALYs over the next eight years.

On the other hand, if the trend of risk factors increases, there will be an increase in health care expenditure of $\$ 7400$ million, (\$245.3 million) and an increase of 766,029 DALYs during the eight-year period. The modelling which was used in this study [16] presented the benefits of investment in primary prevention, which could prevent the number of deaths and also reduce the number of hospital admissions as well as saving costs of acute hospital admissions from CVD in the UK.

\section{Future Work}

This study contributes to the initial CVD cost-offset model for estimating the future burden of CVD events and the future potential benefits of reducing the risk factors of CVD in the population level in Thailand. A more sophisticated and dynamic model can be developed by applying the Markov model or Discrete event simulation model if the specific CVD risk equations and the data are available. The dynamics of the risk factors should be taken into account in any further study because in reality most CVD risk factors are modifiable and can change over time when people change their health behaviour.

\section{Author Contributions}

Conceived and designed the experiments: KK. Supervised the experiments and statistical analysis: IR. Analysed the data under KK supervision: KK. Contributed reagents/materials/analysis tools: KK. Wrote the Paper: IR KK IM MR. Review: KK MR IM.

\section{Conflicts of Interest}

The authors declare no conflicts of interest regarding the publication of this paper. 


\section{References}

[1] Bureau of Non-Communicable Disease, Department of Disease Control, Ministry of Public Health (2010) Annual Report 2009. Office of Veterans Affairs Printing Organization under the Royal Patronage, Thailand.

[2] Asia Pacific Cohort Studies Collaboration (2007) Cholesterol, Diabetes and Major Cardiovascular Diseases in the Asia-Pacific Region. Diabetologia, 50, 2289-2297. https://doi.org/10.1007/s00125-007-0801-2

[3] Aekplakorn, W., et al. (2010) The CVD Risk Factors Profile from the NHESIV in 2009. National Health Examination Survey IV Report 2008-2009. The Graphic System Co., Ltd., Thailand.

[4] International Health Policy Program (2012) Burden of Diseases and Injury in Thailand 2009. The Graphic System, Thailand.

[5] Yusuf, H.R., Giles, W.H., Croft, J.B., Anda, R.F. and Casper, M.L. (1998) Impact of Multiple Risk Factor Profiles on Determining Cardiovascular Disease Risk. Preventive Medicine, 27, 1-9. https://doi.org/10.1006/pmed.1997.0268

[6] Lloyd-Jones, D.M., Larson, M.G., Beiser, A. and Levy, D. (1999) The Lifetime Risk of Developing Coronary Heart Disease. The Lancet, 353, 89-92. https://doi.org/10.1016/S0140-6736(98)10279-9

[7] McGowan, C., Yusuf, S., Islam, S., Jung, H., Rangarajan, S., Avezum, A., Dans, A.L., et al. (2010) Estimating Modifiable Coronary Heart Disease Risk in Multiple Regions of the World: The INTERHEART Modifiable Risk Score. European Heart Journal, 32, 581-589. https://doi.org/10.1093/eurheartj/ehq448

[8] Yusuf, S., Hawken, S., Ôunpuu, S., Dans, T., Avezum, A., Lanas, F. and Lisheng, L. (2004) Effect of Potentially Modifiable Risk Factors Associated with Myocardial Infarction in 52 Countries (the INTERHEART Study): A Case-Control Study. The Lancet, 364, 937-952. https://doi.org/10.1016/S0140-6736(04)17018-9

[9] Bureau of Non-Communicable Disease, Department of Disease Control, Ministry of Public Health (2012) Guideline for Assessment of Cardiovascular Diseases Risk. WVO Office of Printing, War Veterans Organization of Thailand under the Royal Patronage of His Majesty the King, Bangkok, Thailand.

[10] Suet-Lam, M. (1999) Projecting Coronary Heart Disease Incidence and Cost in Australia: Results from the Incidence Module of the Cardiovascular Disease Policy Model. Australian and New Zealand Journal of Public Health, 23, 11-19. https://doi.org/10.1111/j.1467-842X.1999.tb01199.x

[11] Heidenreich, P.A., et al. (2011) Forecasting the Future of Cardiovascular Disease in the United States. Circulation, 123, 933-944.

https://doi.org/10.1161/CIR.0b013e31820a55f5

[12] Kang, H.Y., Lim, S.J., Suh, H.S. and Liew, D. (2011) Estimating the Lifetime Economic Burden of Stroke According to the Age of Onset in South Korea: A Cost of Illness Study. BMC Public Health, 11, Article No. 646.

https://doi.org/10.1186/1471-2458-11-646

[13] Grover, S.A., Paquet, S., Levinton, C., Coupal, L. and Zowall, H. (1998) Estimating the Benefits of Modifying Risk Factors of Cardiovascular Disease: A Comparison of Primary vs Secondary Prevention. Archives of Internal Medicine, 158, 655-662. https://doi.org/10.1001/archinte.158.6.655

[14] Capewell, S., Morrison, C.E. and Mcmurray, J.J. (1999) The Contribution of Modern Cardiovascular Treatment and Risk Factor Changes to the Decline in Coronary Heart Disease Mortality in Scotland between 1975 and 1994. Heart, 81, 380-386. 
https://doi.org/10.1136/hrt.81.4.380

[15] Goldman, 1., et al. (2001) The Effect of Risk Factor Reductions between 1981 and 1990 on Coronary Heart Disease Incidence, Prevalence, Mortality and Cost. Journal of the American College of Cardiology, 38, 1012-1017. https://doi.org/10.1016/S0735-1097(01)01512-1

[16] Whitfield, M.D., et al. (2006) Predicting the Impact of Population-Level Risk Reduction in Cardiovascular Disease and Stroke on Acute Hospital Admission Rates over a 5-Year Period-A Pilot Study. Public Health, 120, 1140-1148. https://doi.org/10.1016/j.puhe.2006.10.012

[17] Moran, A., Gu, D., Zhao, D., Coxson, P., Wang, Y.C., Chen, C.S., Liu, J., Cheng, J., Bibbins-Domingo, K., Shen, Y.M. and He, J. (2010) Future Cardiovascular Disease in China: Markov Model and Risk Factor Scenario Projections from the Coronary Heart Disease Policy Model-China. Circulation. Cardiovascular Quality and Outcomes, 3, 243-252. https://doi.org/10.1161/CIRCOUTCOMES.109.910711

[18] Lim, S.S., Gaziano, T.A., Gakidou, E., Reddy, K.S., Farzadfar, F., Lozano, R. and Rodgers, A. (2007) Prevention of Cardiovascular Disease in High-Risk Individuals in Low-Income and Middle-Income Countries: Health Effects and Costs. The Lancet, 370, 2054-2062. https://doi.org/10.1016/S0140-6736(07)61699-7

[19] Conly, J., Clement, F., Tonelli, M., Hemmelgarn, B., Klarenbach, S., Lloyd, A., Manns, B., et al. (2011) Cost-Effectiveness of the Use of Low- and High-Potency Statins in People at Low Cardiovascular Risk. Canadian Medical Association Journal, 183, E1180-E1188. https://doi.org/10.1503/cmaj.101281

[20] Cobiac, L.J., Magnus, A., Lim, S., Barendregt, J.J., Carter, R. and Vos, T. (2012) Which Interventions Offer the Best Value for Money in Primary Prevention of Cardiovascular Disease? PLoS ONE, 7, e41842. https://doi.org/10.1371/journal.pone.0041842

[21] Mannan, H.R., Knuiman, M. and Hobbs, M. (2008) Adopting a Markov Monte Carlo Simulation Model for Forecasting the Number of Coronary Artery Revascularisation Procedures in an Era of Rapidly Changing Technology and Policy. BMC Medical Informatics and Decision Making, 8, 27. https://doi.org/10.1186/1472-6947-8-27

[22] Dodhia, H., Phillips, K., Zannou, M.I., Airoldi, M. and Bevan, G. (2012) Modelling the Impact on Avoidable Cardiovascular Disease Burden and Costs of Interventions to Lower SBP in the England Population. Journal of Hypertension, 30, 217-226. https://doi.org/10.1097/HJH.0b013e32834d86ee

[23] Aekplakorn, W. (2010) Thai National Health Examination Survey, NHES IV. The Graphic System Co., Ltd., Nonthaburi.

[24] Barzi, F., Patel, A., Gu, D., Sritara, P., Lam, T.H., Rodgers, A. and Woodward, M. (2007) Cardiovascular Risk Prediction Tools for Populations in Asia. Journal of Epidemiology and Community Health, 61, 115-121. https://doi.org/10.1136/jech.2005.044842

[25] Mathers, C.D., Vos, T., Lopez, A.D., Salomon, J. and Ezzati, M. (2001) National Burden of Disease Studies: A Practical Guide. World Health Organization, Geneva.

[26] Drummond, M.F., Sculpher, M.J., Torrance, G.W., O’Brien, B.J. and Stoddart, G.L. (2005) Methods for the Economic Evaluation Of Health Care Programmes. 3rd Edition, Oxford University Press, Oxford.

[27] Murray, C.J.L. and Lopez, A.D. (1996) Global Burden of Disease and Injury Series. Volume 1. The Global Burden of Disease: A Comprehensive Assessment of Mortality and Disability from Disease, Injuries and Risk Factors in 1990 and Projected to 
2020. Harvard University Press, Cambridge.

[28] Bundhamcharoen, K., Odton, P., Phulkerd, S. and Tangcharoensathien, V. (2011) The Burden of Disease in Thailand: Changes in Health Gap between 1999 and 2004. BMC Public Health, 11, 53. https://doi.org/10.1186/1471-2458-11-53

[29] World Health Organization (2016) DisMod II. https://www.epigear.com/index_files/dismod_ii.html

[30] Barendregt, J.J. (2010) EpiGear International. https://www.epigear.com/

[31] Inthawong, R. (2015) Assessing the Impact of Reducing Risk Factors for Cardiovascular Disease in Thailand. Doctoral Dissertation, Sheffield Hallam University, United Kingdom.

[32] Allen, L., Cobiac, L. and Townsend, N. (2017) Quantifying the Global Distribution of Premature Mortality from Non-Communicable Diseases. Journal of Public Health, 39, 698-703. https://doi.org/10.1093/pubmed/fdx008

[33] World Health Organization (2000) Standard Life Table West Level 26 [Computer Program]. http://www.who.int/healthinfo/bodreferencestandardlifetable.xls

[34] Kontis, V., Mathers, C.D., Rehm, J., Stevens, G.A., Shield, K.D., Bonita, R. and Ezzati, M. (2014) Contribution of Six Risk Factors to Achieving the $25 \times 25$ NonCommunicable Disease Mortality Reduction Target: A Modelling Study. The Lancet, 384, 427-437. https://doi.org/10.1016/S0140-6736(14)60616-4

[35] World Health Organization (2011) Global Status Report on Non-Communicable Diseases 2010. WHO Press, Geneva, Switzerland. http://whqlibdoc.who.int/publications/2011/9789240686458_eng.pdf

[36] Sangthong, R., Chongsuvivatwong, V., Geater, A.F. and Jitpiboon, W. (2011) Decreasing Trends of Smoking and Smoking Cessation in Successive Thai Birth Cohorts: Age-Period-Cohort Analysis from 1991-2007 National Surveys. Asian Pacific Journal of Cancer Prevention, 12, 3081-3085.

[37] Knodel, J. and Chayovan, N. (2008) Population Ageing and the Well-Being of Older Persons in Thailand: Past Trends, Current Situation and Future Challenges. UNFPA Thailand and Asia and the Pacific Regional Office.

[38] Inthawong, R., Khatab, K., Whitfield, M., et al. (2019) Application of Cardiovascular Disease (CVD) Risk Assessment Equations to the Thai Population. Biostatistics \& Epidemiologya, 2, 18. https://doi.org/10.30881/beij.00013 


\section{Appendix}

The probability of death in the Thai population from 1996 to 2006. The probability of death from CVD has been calculated from the number of death from CVD divided by the number of mid-year population each year and classified by age group and gender.

Table A1. Probability of dying from all CVD (1996-2006) in the Thai population.

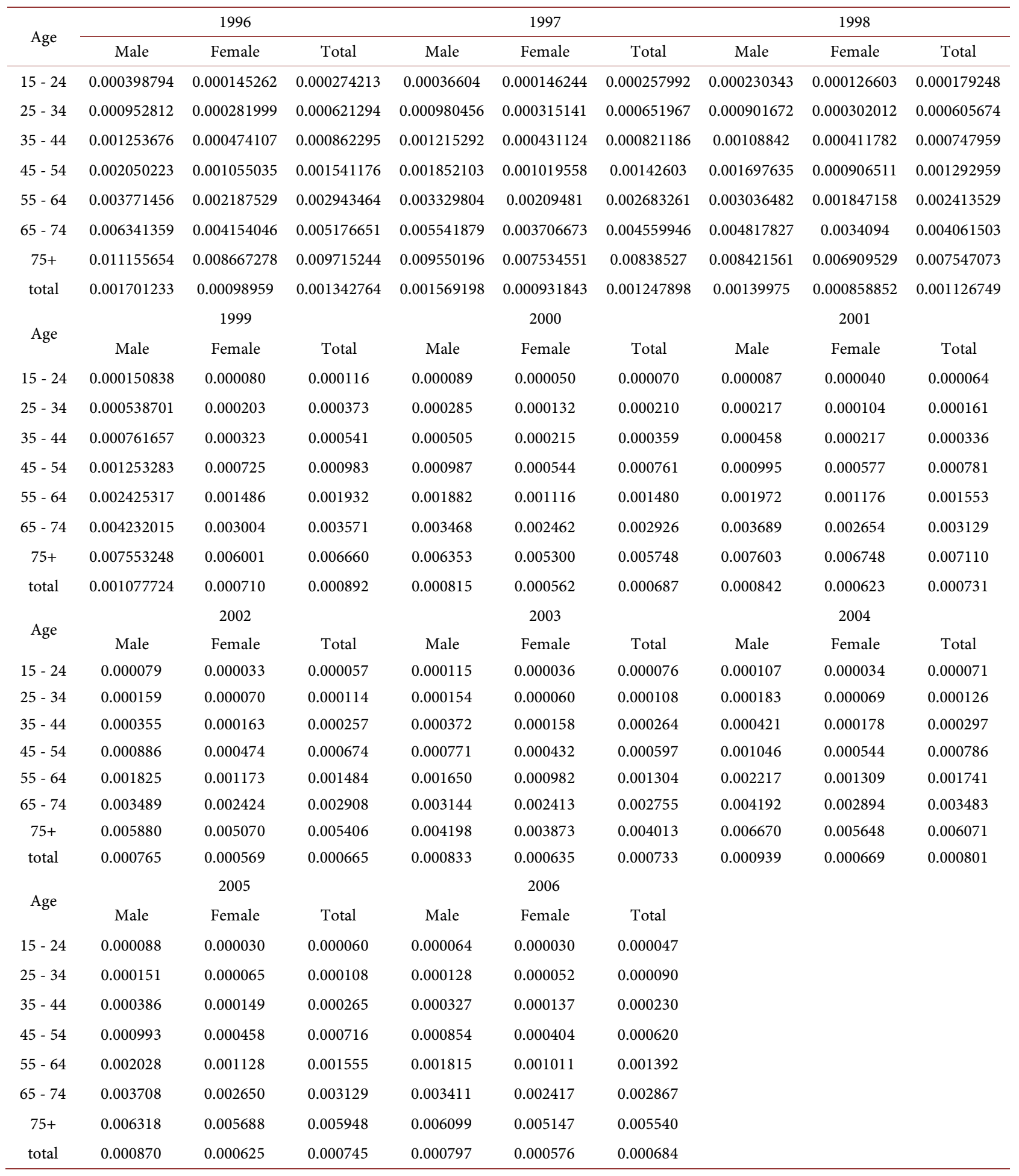


Table A2. Showing the average 10-year probability of dying from CVD classified by age group and gender.

\begin{tabular}{cccc}
\hline Age & \multicolumn{2}{c}{ Average 10-years probabilities } \\
\cline { 2 - 3 } & Male & Female & Total \\
\hline $5-24$ & 0.0001615 & 0.0000682 & 0.0001157 \\
$25-34$ & 0.0004228 & 0.0001504 & 0.0002881 \\
$35-44$ & 0.0006494 & 0.0002597 & 0.0004527 \\
$45-54$ & 0.0012168 & 0.0006489 & 0.0009253 \\
$55-64$ & 0.0023593 & 0.0014100 & 0.0018620 \\
$65-74$ & 0.0041849 & 0.0029262 & 0.0035060 \\
$75+$ & 0.0072546 & 0.0060533 & 0.0065584 \\
total & 0.0010553 & 0.0007045 & 0.0008777 \\
\hline
\end{tabular}

Table A3. The disability weight of the cardiovascular disease from GBD study 2010.

\begin{tabular}{|c|c|c|}
\hline Cardiovascular and circulatory disease & Estimate & $95 \%$ CI \\
\hline Acute myocardial infarction: days 1 - 2 & 0.422 & $0.284-0.566$ \\
\hline Acute myocardial infarction: days 3 - 28 & 0.056 & $0.035-0.082$ \\
\hline Angina pectoris: mild & 0.037 & $0.022-0.058$ \\
\hline Angina pectoris: moderate & 0.066 & $0.043-0.095$ \\
\hline Angina pectoris: severe & 0.167 & $0.109-0.234$ \\
\hline Cardiac conduction disorders and cardiac dysrhythmias & 0.145 & $0.097-0.205$ \\
\hline Claudication & 0.016 & $0.008-0.028$ \\
\hline Heart failure: mild & 0.037 & $0.021-0.058$ \\
\hline Heart failure: moderate & 0.07 & $0.044-0.102$ \\
\hline Heart failure: severe & 0.186 & $0.128-0.261$ \\
\hline Stroke: long-term consequences, mild & 0.021 & $0.011-0.037$ \\
\hline Stroke: long-term consequences, moderate & 0.076 & $0.050-0.110$ \\
\hline Stroke: long-term consequences, moderate plus cognition problems & 0.312 & $0.211-0.433$ \\
\hline Stroke: long-term consequences, severe & 0.539 & $0.363-0.705$ \\
\hline Stroke: long-term consequences, severe plus cognition problems & 0.567 & $0.394-0.738$ \\
\hline
\end{tabular}

Source: Murray, C. J., \& Lopez, A. D. (2013). Measuring the global burden of disease. New England Journal of Medicine, 369(5), 448-457.

Table A4. Mean (95\% CI) of blood pressure trends (crude estimate) for the population aged 25 years and over in Thailand (mmHg).

\begin{tabular}{cccccccccccc}
\hline & 1980 & 1981 & 1982 & 1983 & 1984 & 1985 & 1986 & 1987 & 1988 & 1989 \\
\hline \multirow{2}{*}{ Male } & 121.3 & 121.3 & 121.2 & 121 & 120.9 & 120.9 & 120.8 & 120.8 & 120.9 & 121 \\
& $(112.3$ & $(113.1$ & $(113.8$ & $(114.4$ & $(114.9$ & $(115.3$ & $(115.7$ & $(116.1$ & $(116.5$ & $(116.8$ \\
& - & - & - & - & - & - & - & - & - & - \\
& $130.3)$ & $129.2)$ & $128.2)$ & $127.4)$ & $126.7)$ & $126.1)$ & $125.7)$ & $125.3)$ & $125.2)$ & $125.1)$ \\
\hline
\end{tabular}




\section{Continued}

\begin{tabular}{|c|c|c|c|c|c|c|c|c|c|c|}
\hline \multirow[t]{5}{*}{ Female } & 116.6 & 116.7 & 116.8 & 116.9 & 117 & 117 & 117.1 & 117.2 & 117.3 & 117.4 \\
\hline & (107.6 & (108.6 & (109.4 & (109.9 & (110.7 & (111.3 & (111.7 & (112.1 & (112.6 & (113.1 \\
\hline & - & - & - & - & - & - & - & - & - & - \\
\hline & 126.0) & 125.2) & 124.4) & 123.7) & 123.2) & 122.7) & 122.3) & 122.0) & 121.8) & 121.7) \\
\hline & 1990 & 1991 & 1992 & 1993 & 1994 & 1995 & 1996 & 1997 & 1998 & 1999 \\
\hline \multirow[t]{4}{*}{ Male } & 121.1 & 121.3 & 121.5 & 121.7 & 121.9 & 122.2 & 122.4 & 122.6 & 122.8 & 122.9 \\
\hline & (117.1 & (117.4 & (117.7 & (118.0 & (118.3 & (118.6 & (118.9 & (119.1 & (119.2 & (119.4 \\
\hline & - & - & - & - & - & - & - & - & - & - \\
\hline & 125.2) & 125.2) & 125.3) & 125.4) & 125.6) & 125.8) & 126.1) & 126.4) & 126.4) & 126.5) \\
\hline \multirow[t]{5}{*}{ Female } & 117.6 & 117.8 & 117.9 & 118.1 & 118.4 & 118.6 & 118.8 & 133.9 & 119.1 & 119.3 \\
\hline & (113.5 & (113.8 & (114.2 & (114.5 & (114.8 & (115.1 & (115.4 & (125.9 & (115.8 & (116.0 \\
\hline & - & - & - & - & - & - & - & - & - & - \\
\hline & 121.6) & 121.7) & 121.7) & 121.8) & 121.9) & 122.1) & 122.2) & 141.7) & 122.5) & 122.7) \\
\hline & 2000 & 2001 & 2002 & 2003 & 2004 & 2005 & 2006 & 2007 & 2008 & 2009 \\
\hline \multirow[t]{4}{*}{ Male } & 123.1 & 123.2 & 123.4 & 123.6 & 123.8 & 124.1 & 124.3 & 124.5 & 127.4 & 124.8 \\
\hline & (119.7 & (119.9 & (120.2 & (120.5 & (120.7 & (120.9 & (121.1 & (121.1 & (121.0 & (120.6 \\
\hline & - & - & - & - & - & - & - & - & - & - \\
\hline & 126.6) & 126.7) & 126.8) & 126.9) & 127.1) & 127.3) & 127.6) & 128.0) & 128.5) & 129.1) \\
\hline \multirow[t]{4}{*}{ Female } & 119.5 & 119.7 & 119.8 & 120 & 120.2 & 120.4 & 120.6 & 120.8 & 120.9 & 121 \\
\hline & (116.2 & (116.5 & (116.7 & (116.8 & (117.1 & (117.2 & (117.2 & (117.1 & (116.9 & (116.6 \\
\hline & - & - & - & - & - & - & - & - & - & - \\
\hline & 122.8) & 122.8) & 123.0) & 123.2) & 123.5) & 123.8) & 124.1) & 124.5) & 124.9) & 125.4) \\
\hline
\end{tabular}

Table A5. Mean (95\% CI) of the total cholesterol trends (crude estimate) for population aged 25 years and over in Thailand $(\mathrm{mmol} / \mathrm{L})$.

\begin{tabular}{cccccccccccc}
\hline & 1980 & 1981 & 1982 & 1983 & 1984 & 1985 & 1986 & 1987 & 1988 & 1989 \\
\hline Male & 4.7 & 4.7 & 4.7 & 4.7 & 4.7 & 4.7 & 4.7 & 4.7 & 4.7 & 4.7 \\
& $(3.9-5.4)$ & $(4.0-5.3)$ & $(4.0-5.3)$ & $(4.1-5.2)$ & $(4.1-5.2)$ & $(4.2-5.1)$ & $(4.3-5.1)$ & $(4.3-5.1)$ & $(4.3-5.0)$ & $(4.4-5.0)$ \\
Female & 4.7 & 4.7 & 4.7 & 4.7 & 4.7 & 4.7 & 4.7 & 4.7 & 4.7 & 4.7 \\
& $(3.8-5.6)$ & $(3.9-5.5)$ & $(3.9-5.4)$ & $(4.0-5.3)$ & $(4.1-5.3)$ & $(4.2-5.2)$ & $(4.2-5.2)$ & $(4.3-5.1)$ & $(4.3-5.1)$ & $(4.4-5.1)$ \\
& 1990 & 1991 & 1992 & 1993 & 1994 & 1995 & 1996 & 1997 & 1998 & 1999 \\
Male & 4.7 & 4.7 & 4.8 & 4.8 & 4.8 & 4.8 & 4.8 & 4.9 & 4.9 & 4.9 \\
& $(4.4-5.0)$ & $(4.5-5.0)$ & $(4.5-5.0)$ & $(4.5-5.0)$ & $(4.5-5.1)$ & $(4.6-5.1)$ & $(4.6-5.1)$ & $(4.6-5.1)$ & $(4.6-5.1)$ & $(4.6-5.1)$ \\
Female & 4.8 & 4.8 & 4.8 & 4.8 & 4.8 & 4.9 & 4.9 & 4.9 & 4.9 & 4.9 \\
& $(4.4-5.1)$ & $(4.4-5.1)$ & $(4.5-5.1)$ & $(4.5-5.1)$ & $(4.5-5.2)$ & $(4.5-5.2)$ & $(4.6-5.2)$ & $(4.6-5.2)$ & $(4.6-5.3)$ & $(4.6-5.3)$ \\
& 2000 & 2001 & 2002 & 2003 & 2004 & 2005 & 2006 & 2007 & 2008 & 2009 \\
Male & 4.4 & 4.3 & 5 & 5 & 5 & 5 & 5.1 & 5.1 & 5.1 & 5.2 \\
& $(3.8-4.9)$ & $(3.8-4.9)$ & $(4.7-5.2)$ & $(4.8-5.2)$ & $(4.8-5.2)$ & $(4.8-5.3)$ & $(4.8-5.3)$ & $(4.9-5.3)$ & $(4.9-5.4)$ & $(4.5-5.4)$ \\
Female & 4.9 & 4.9 & 5 & 5.1 & 5.1 & 5.1 & 5.1 & 5.2 & 5.2 & 5.3 \\
& $(4.7-5.2)$ & $(4.7-5.2)$ & $(4.7-5.3)$ & $(4.8-5.3)$ & $(4.8-5.4)$ & $(4.9-5.4)$ & $(4.9-5.4)$ & $(4.9-5.5)$ & $(4.9-5.5)$ & $(4.9-5.6)$ \\
\hline
\end{tabular}


Table A6. Average change in the level of risk factors between 1980 and 2009 in the Thai population who aged 25 years and over.

\begin{tabular}{cccccc}
\hline \multirow{2}{*}{ Risk Factors } & \multicolumn{2}{c}{ Average change per year } & \multicolumn{3}{c}{ \% Change between 1980 to 2009 } \\
\cline { 2 - 6 } & Male & Female & Male & Female & Total \\
\hline Blood pressure (mmHg) & 6.1 & 4.3 & 2.9 & 3.8 & 3.35 \\
Total cholesterol (mmol/L) & 0.4 & 0.5 & 10.6 & 12.8 & 11.70 \\
\hline
\end{tabular}

